\title{
Bilateral renal cortical necrosis associated with calcification: report of a case and a review of aetiology
}

\author{
M. J. PHILLIPS 1 \\ From the Royal Air Force Institute of Pathology and Tropical Medicine, Halton
}

SYNOPSIS Clinico-pathological details are given of a patient who survived bilateral renal cortical necrosis for 44 days as a result of treatment by haemodialysis. Cortical calcification was demonstrable radiologically in life and at necropsy.

The literature pertaining to renal ischaemic damage and calcification is reviewed. Conclusions are drawn as to the mechanism that produces renal cortical calcification in the light of previous experimental work and the study of the present case.

It is suggested that the widespread use of haemodialysis in treatment is likely to result in the detection of an increasing number of such cases.

Renal calcification following bilateral cortical necrosis is rare. It was not found by Sheehan and Moore (1952) in 34 cases nor was it referred to by Ober, Reid, Romney, and Merrill (1956) in a study of 80 renal lesions in pregnancy which included seven patients with renal cortical necrosis. Wells, Margolin, and Gall (1960) similarly did not mention calcification as a feature of any of 21 such patients studied clinically and pathologically. Gormsen, Iversen, and Raaschou (1955), in a review of renal biopsy in acute anuria, described a survival from renal cortical necrosis in which diffuse bilateral renal calcification was demonstrated radiologically 61 days after onset. In 1957, Gjørup, Killman, and Thaysen reported on a patient who survived cortical necrosis for 51 days; calcification was demonstrated by biopsy at 30 days and was found in greater degree at necropsy. Robson (1961) has also described a patient in whom calcification was demonstrated radiologically six weeks after the onset of acute renal failure.

Unusually prolonged survival is the feature common to these three cases. The patient described in this paper lived for $\mathbf{4 4}$ days and, like the three previous cases, had been treated by haemodialysis.

A 23-year-old woman was admitted to hospital in the 37th week of her second pregnancy, suffering from a

'Present address: R.A.F. Hospital, Aden.

Received for publication 16 October 1961. concealed accidental haemorrhage. She was shocked and hypotensive with a blood pressure of $80 / 30 \mathrm{~mm} . \mathbf{H g}$; laboratory investigation revealed a hypofibrinogenaemia. Treatment by blood transfusion and intravenous administration of fibrinogen resulted in rapid clinical improvement and raising of the blood pressure to $110 / 80 \mathrm{~mm}$. $\mathrm{Hg}$. Surgical induction of labour was then carried out, the patient giving birth to a stillborn infant; during parturition approximately $1,000 \mathrm{ml}$. of blood was lost, a great proportion of which was of retroplacental origin. The patient was oliguric from the start, passing only $60 \mathrm{ml}$. of urine in the first and even less during the second 24 hours; the blood urea on the second day was $80 \mathrm{mg}$. per $100 \mathrm{ml}$.

On the third day the patient was transferred to a renal unit where she remained vir tually anuric; haemodialysis with a Kolff twin-coil artificial kidney was carried out 10 days after the onset of oliguria. There was immediate improvement in her condition but the oliguria continued; further dialyses were carried out 23 and 33 days after the onset. Despite this, the patient died in uraemia on the forty-fourth day of her illness. An abdominal radiograph taken on the thirty-eighth day (Fig. 1) showed a marked degree of bilateral renal calcification which involved the cortices, whereas one taken at 22 days did not show this.

\section{PATHOLOGICAL FINDINGS IN THE KIDNEYS}

The main findings at necropsy were in the pancreas and kidneys. A description of the pancreatic lesion (an avascular necrosis) will be published elsewhere 


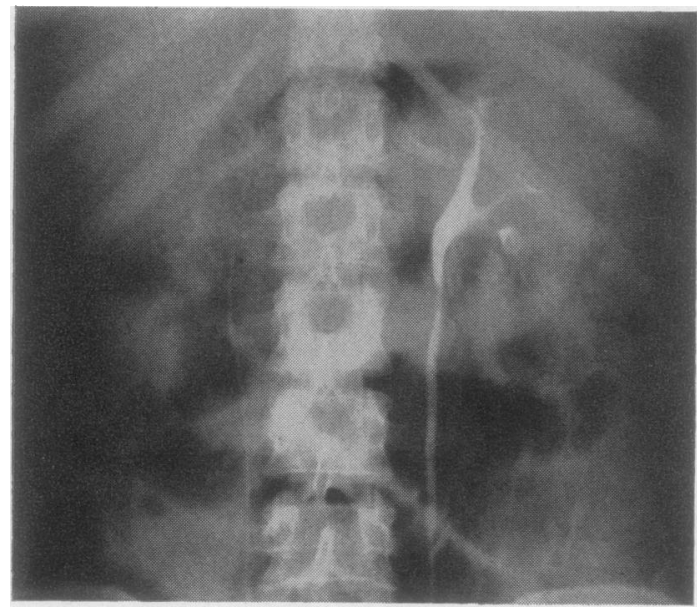

FIG. 1. Retrograde pyelogram performed on the thirtyeighth day of illness. The calcified cortices are well outlined.

(Heard and Phillips, 1961) and it will not be considered further in this paper.

MACROSCOPIC FEATURES The right kidney weighed $100 \mathrm{~g}$. and the left $90 \mathrm{~g}$. Both were obviously

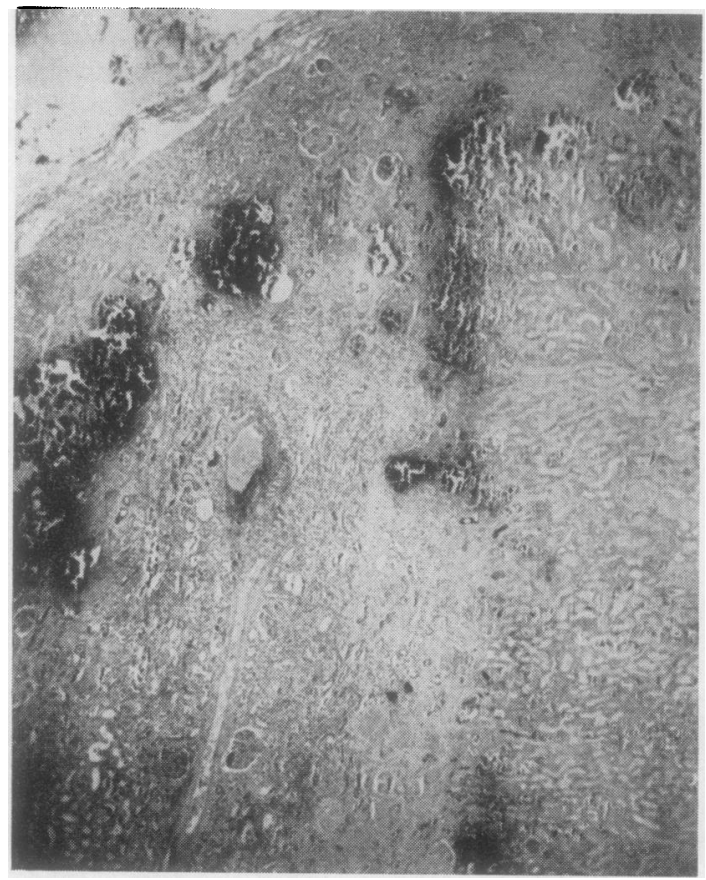

FIG. 2. Kidney. Calcification affects the whole of the small necroses but only the margins of the large necroses are involved. Haematoxylin and eosin $\times 50$. shrunken, the outer surfaces showing an irregular $\underline{\underline{\sigma}}$ coarse granularity and general pallor. The capsules were easily stripped, and there was no atheroma, $\stackrel{\vec{\rho}}{+}$ thrombus, embolus, or other obstructive lesion in 0 the renal arteries; the renal veins were also normal. 흐

The cut surfaces showed a necrotic, narrowed, $\frac{\bar{m}}{\bar{T}}$ yellow-white cortical layer. The degree of necrosis, $\stackrel{\mathbb{Q}}{\Omega}$ as judged by the classification of Sheehan and Moore 0 (1952), was patchy. The only large area of surviving cortical tissue was in the juxta-medullary region, which was sharply demarcated from the necrosed $\vec{\omega}$ cortex by a dark haemorrhagic line. There were $\stackrel{\sigma}{\Omega}$ only small scattered areas of surviving cortical 용 tissue in the subcapsular region, and the columns $\vec{r}$ of Bertini were as much involved in the necrotic process as was the remainder of the cortex. $\dot{\omega}$ Calcification was not apparent to the naked eye, but a gritty sensation was imparted to the knife. The renal pelves were normal: both ureters were patent and anatomically normal; the bladder, which contained a few millilitres of dark urine, was normal.

MICROSCOPIC FEATURES The affected areas of cortex $\vec{\bullet}$ showed total necrosis involving glomeruli, inter- ? stitium, and tubules. The interlobular and arcuate arteries of these areas were necrosed and contained

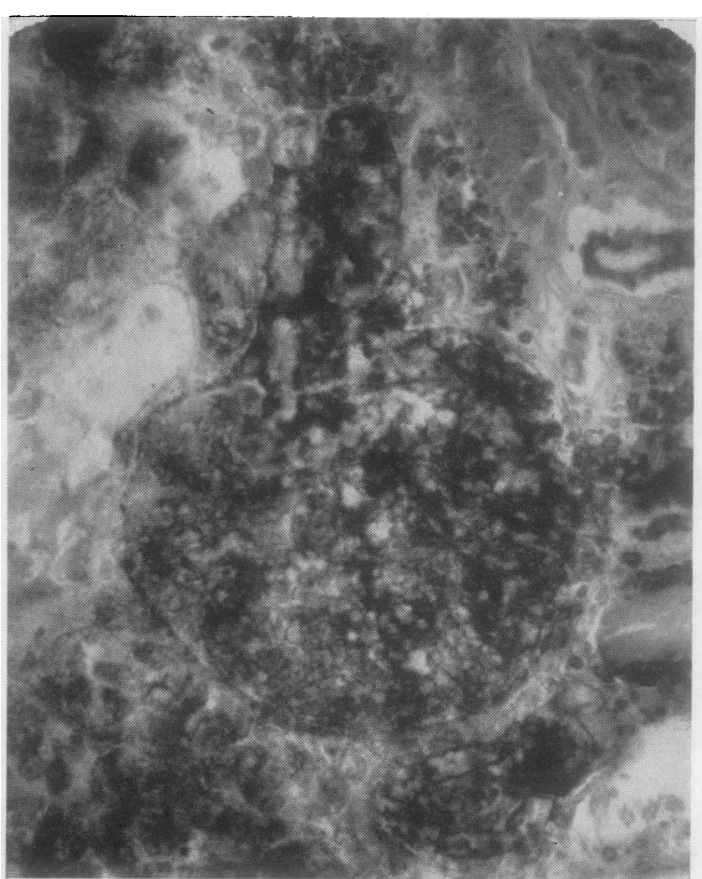

FIG. 3. Kidney. There is calcification in the glomerular tuft and in the afferent arteriole. Naphthachrome green $\times 320$. 
thrombi, most of which were undergoing, or had undergone, fibrous organization. The small portions of cortex not involved in the necrotic process were remarkably well preserved and, from a histological standpoint, appeared capable of producing normal urine; the total area of surviving cortex, however, was very small.

Calcification was an outstanding feature of the necrosed areas, and affected the whole of the small necroses but only the outer margins of the large ones (Fig. 2). The walls of the arteries and glomerular capillaries were particularly involved in the calcifying process (Fig. 3). The medullary portions of the kidney were relatively normal except for the presence of haem casts in many of the collecting tubules. There was no evidence of pre-existing renal disease.

\section{DISCUSSION}

The first account of experimental work on renal calcification was given by Litten (1881). He produced ischaemic infarcts in dog kidneys by occlusion of the renal vessels and noted that whereas permanent arterial occlusion led to non-calcified infarcts, temporary occlusion for one and a half to two hours was followed by deposition of calcium in the infarcted parenchyma. Edwards (1958) also investigated the effects of ischaemia on dog kidneys. In one group of dogs he produced temporary ischaemia of a kidney by occluding the renal artery for four and a half hours, having removed the contralateral kidney in order to precipitate acute uraemia. Calcification of the damaged renal parenchyma occurred in all of these cases. A number of the dogs in this group were haemodialysed by means of an artificial kidney (Skeggs, Leonards, and Heisler, 1949) without any apparent effect on the amount or distribution of the calcification. A control group of dogs was not subjected to removal of the contralateral kidney; no calcification occurred in the infarcted areas whether the arterial occlusion was permanent or temporary. The longer the survival time of the uraemic group of animals, the greater was the degree of calcification and this could be followed radiographically, no calcification being seen in any animal which survived less than five days. Microscopical assessment of the calcification showed that it was related to the regions of more severe parenchymatous damage, and was particularly pronounced at the margins of large infarcts; there was no calcification within the centre of large infarcts and it appeared that the calcifying process only occurred at the junction of dead and viable tissue. The microscopical appearances of the case described in this paper were very similar to these experimental findings, particularly as to the restriction of calcification to the edges of large areas of necrosis.

This elegant study of Edwards established that calcification in dog kidneys only occurred when there was a renewal of renal blood flow after a short period of ischaemia and that renal failure was a necessary prerequisite. These conclusions were apparently contradicted by a study on rat kidneys by Gruhn and Fisher (1960) who produced dystrophic calcification in infarcts which had been induced by permanent occlusion of the renal vessels; but this anomaly was explained on the finding that vascular anastomoses had occurred between the capsule and adjacent renal tissue.

Snapper and Gechman (1956) noted that all tissues in which dystrophic calcification occurred were rich in chondroitin sulphuric acid and suggested that this acid may act as a cation exchange resin capable of concentrating calcium. Fisher and Gruhn (1960) found a local increase in chondroitin sulphuric acid and calcium at the site of renal necrosis and felt that the increase must be derived from circulating blood rather than from pre-existent trapped plasma. This provides further suggestive evidence that a normal blood supply to the tissue adjacent to the damaged areas is a prerequisite for calcification to occur in areas of renal necrosis.

In another set of animal experiments Hepler and Simonds (1945) produced renal necrosis by subjecting the kidneys to chemical nephrotoxins. Dystrophic calcification occurred in the necrosed areas and was associated in these areas with a depletion or absence of tissue alkaline phosphatase. This was confirmed by Gruhn and Fisher (1960) in their experimental work on rat kidneys in which they produced first dystrophic calcification and then heterotopic ossification. They found that tissue alkaline phosphatase was absent in the stage of dystrophic calcification but was present and necessary for the later process of ossification.

POSSIBLE MECHANISM OF PRODUCING DYSTROPHIC CALCIFICATION These experimental data, particularly those of Edwards, throw some light on the possible mechanisms of producing dystrophic calcification in renal cortical necrosis.

Extent The amount of tissue damage is obviously of great importance. Too little would result in fibrosis; too much in conditions where there is insufficient normal renal tissue available for the re-establishment of blood flow through adjacent areas of necrosed and normal parenchyma, and, therefore, no calcification would occur. Thus, one would not expect to find calcification in gross or 
minor degrees of renal cortical necrosis (Sheehan and Moore's classification) but would find it in the patchy and more severe focal varieties.

Time There must be an optimum time interval between the onset of necrosis and the deposition of calcium. In the animal experiments of Edwards and others this interval was three to four days. This early appearance does not seem to be associated with human renal cortical necrosis. Sheehan and Moore's 34 patients all died within 21 days of onset, and no calcification was seen. Only five out of the 21 patients described by Wells et al. (1960) survived longer than 14 days (maximum 31 days) and, again, no calcification was seen. The patient of Gormsen et al. (1955) showed no evidence of calcification in renal biopsy specimens at seven and 11 days but did show it radiographically at 61 days. Robson's (1961) patient showed radiographic evidence at six weeks; that of Gjørup et al. (1957) showed calcification in a renal biopsy specimen at 30 days; and in the case described here there was radiographic evidence at 38 days but none at 22 days. Renal cortical necrosis in a patient who survived for 28 days was described by Joekes and Bull (1948) and no calcification was found. It would appear that a period of the order of $\mathbf{3 0}$ days has to elapse before calcification of the kidneys occurs in human renal cortical necrosis.

Treatment by haemodialysis Survival periods of this order can be directly attributed to treatment with an artificial kidney. This was certainly true in the patient described in this paper and was probably so in that of Gjørup et al. (1957). Edwards (1958) found no evidence that dialysis of itself increases the precipitation of calcium salts in a damaged kidney and, although it is true that dialysis causes a relatively sharp rise in serum calcium levels, which are generally low in acute renal failure, there is no reason to believe that such a mechanism played any part in the renal calcification described here. The serum calcium levels were estimated before and after the second dialysis; the predialysis level was $3.1 \mathrm{mEq} . / 1$. (6.2 $\mathrm{mg}$./100 ml.) and the post-dialysis was within the normal range, $4.9 \mathrm{mEq}$./l. (9.8 mg./100 ml.). Moreover, Gruhn and Fisher (1960) found that dystrophic calcification in rat kidneys occurred independently of serum calcium and alkaline phosphatase levels and, although no actual proof can be given, it is felt that this is also true of the calcifying process in human renal cortical necrosis, in which the changes are of a local nature. The marked affinity of the precipitated calcium for the walls of necrosed vessels in the case described accentuates this point and lends weight to the concept of arterial spasm followed by arterial necrosis as the pathogenetic sequence of renal 을 cortical necrosis; the process of necrosis, re- $\Rightarrow$ establishment of blood supply, and calcification $\stackrel{5}{7}$ already described as applying to the renal parenchyma is equally applicable to the vascular walls which would be the first tissues affected by arterial spasm.

\section{CONCLUSION}

This study of a case and of the previous literature induces the following conclusions as to the pathogenesis of renal calcification in renal cortical necrosis.

1 The basic lesion is one of arterial spasm followed $\vec{c}$ by arterial necrosis. The extent and distribution of $\underline{\omega}$ the resulting necrosis of the renal parenchyma depends on the degree of arterial involvement.

2 Re-establishment of blood supply to the $\vec{c}$ surviving renal cortex in contact with necrotic tissue is essential to the production of dystrophic calcification. It follows that the relative proportions $₹$ of viable and dead tissue are critical to its formation. $\overrightarrow{6}$

3 The exact physico-chemical processes con- N cerned in dystrophic calcification are not fully understood but experimental evidence indicates that chondroitin sulphuric acid plays an important part.

4 Time is essential for the production of renal dystrophic calcification. At least $\mathbf{3 0}$ days is necessary in human cases of cortical necrosis.

5 Hitherto, survival for 30 days following cortical necrosis of the severity necessary for calcification has been rarely attained. The syndrome of renal cortical calcification following necrosis is, therefore, positively associated with prolonged $:$ survival following treatment by haemodialysis. Such treatment is rapidly becoming commonplace $\delta$ and it is probable that cases similar to that described $₹$ in this paper, extending even to adequate restoration $ᄋ$ of kidney function, will become more frequent. The progress and ultimate fate of such patients may serve to solve many of the outstanding problems in the production of dystrophic calcification and, or at the same time, indicate the ultimate value and $N$ limitations of this method of treatment.

The patient described was admitted to the Renal Unit, Princess Mary's Royal Air Force Hospital, Halton, under the care of Group Captain R. C. Jackson; I am $\mathbb{D}$ indebted to him and his staff for permission to quote? from their clinical records and for their helpful advice. $T$ I am also grateful to my colleagues at the Royal Air $\stackrel{\vec{\Phi}}{\vec{P}}$ Force Institute of Pathology for their critical assistance. The Director General of Medical Services, Royal Air $\overrightarrow{\mathbb{Q}}$ Force, has kindly given permission for publication. 


\section{REFERENCES}

Edwards, E. (1958). J. Urol. (Baltimore), 80, 160.

Fisher, E. R., and Gruhn, J. R. (1960). Unpublished observations, quoted by Gruhn and Fisher.

Gjørup, S., Killman, S. A., and Thaysen, J. H. (1957). Acta med. scand., 158, 47.

Gormsen, H., Iversen, P., and Raaschou, F. (1955). Amer. J. Med., 19, 209.

Gruhn, J., and Fisher, E. R. (1960). A.M.A. Arch. Path., 69, 82.

Heard, B. E., and Phillips, M. J. (1961). In press.

Hepler, O. E., and Simonds, J. P. (1945). Arch. Path. (Chicago), 40, 37.

Joekes, A. M., and Bull, G. M. (1948). Proc. roy. Soc. Med., 41, 678.
Litten, M. (1881). Virchows Arch. path. Anat., 83, 508.

Ober, W. E., Reid, D. E., Romney, S. L., and Merrill, J. P. (1956). Amer. J. Med., 21, 781.

Robson, J. S. (1961). Patterns of Renal Insufficiency. Sydney Watson Smith Lecture, Royal College of Physicians, Edinburgh. In press.

Sheehan, H. L., and Moore, H. C. (1952). Renal Cortical Necrosis and the Kidney of Concealed Accidental Haemorrhage. Blackwell, Oxford.

Skeggs, L. T., Leonards, J. R., and Heisler, C. R. (1949). Proc. Soc. exp. Biol. (N.Y.), 72, 539 .

Snapper, I., and Gechman, E. (1956). In Etiologic Factors in Renal Lithiasis, ed. A. J. Butt, p. 53. Thomas, Springfield.

Wells, J. D., Margolin, E. G., and Gall, E. A. (1960). Amer. J. Med., 29, 257. 